\title{
DESCALING OF PRODUCTION TUBING USING HIGH PRESSURE ATOMISERS
}

\author{
Dr. Nripanka Das \\ $\mathrm{PhD}$ (h.c), MSc, B.Tech
}

\begin{abstract}
One of the extensive problems in oil industry is enhancing the process of oil extraction in arduous geological and technological conditions. This is due to the assumption of most of the high-yield oil fields of the country in late stage development and the growing proportion of hard to recover reserves to their total (Guskova et al., 2011). This mechanism of oil extractions becomes significantly convoluted because of high water cut production wellbore and formation of organic and inorganic deposits.
\end{abstract}

Water factor is a fundamental part in the development and exploration of oil fields. Due to the process of flooding, formation of scale initiates. Scale, formed at the downhole equipment, results in reduction in productivity, costly workover, premature failure of the pumping equipment, thus deteriorating the economic indices of diverse oil and gas firms. Scale is an assemblage of hard, inorganic crystals that cake perforations, casing, production tubing and restricts fluid flow. In USA, productivity of oil wells has been estimated to be declined due to scale formation in production tubing.

High pressure flat fan atomizers can provide a possible solution to the problem of scale formation and has significant advantages over other conventional methods. The overall aim of this research study is to investigate the characteristics of a flat fan nozzle system and critically analyze its effect on scale removal. This study proposes a new technique to address the problem and lay the foundations for a methodology of descaling in oil and gas wells. It furnishes a basic introduction to scale detected in various oil field operations and sources of scale formation. It also provides a synopsis of the schematic design of the apparatus which utilizes high pressure water atomizers with high impact force for scale removal and highlights the results and analysis obtained through calculation of spray impact (theoretical).

\section{Keywords - Descaling, Atomizers, Scale Formation}

\section{INTRODUCTION}

The fundamental objective of oil industry implicates increasing efficiency during oil extraction. A key step in this direction is associated with dealing with the complications of scale formation in the course of well operation. Scale cake build up are commonly observed in perforations, production tubing, pumps, valves, casing and downhole completion equipment which results in wellbore clogging and restricts flow of fluid. Primary elements of deposits in oil field includes $\mathrm{CaCO}_{3}$ (Calcium Carbonate), $\mathrm{CaSO}_{4}$ (Calcium Sulphate) and $\mathrm{BaSO}_{4}$ (Barium Sulphate). Pure scale is rarely found in deposits in oil wells. It generally comprises of an amalgamation of various inorganic compounds mixed with corrosion products, sand particles, and few are coated with substances like asphalt, resin and paraffin. (Mackay et al., 2003; Moghadasi et al., 2003a).

Scales are commonly formed in three patterns:

- Thin incrustation/Loose flakes

- Stratified form

- Crystal form

Loose flakes or thin incrustation holds a permeable and loose geometry and hence are easily removed. Gypsum creating layers of crystals and bunching of slivers are classified under stratified form which fills the entire section of pipe (Bayona, 1993; Andersen et al., 2000; Paulo et al., 2001). Barite and Anhydrites forms dense, solid and impermeable crystal structures.

Radioactive salts of Barium found across mineralized produced water in oil fields are highly compact and most hard to out scale. Concentration of this mineralized water ranges from $0.15 \mathrm{gpl}$ to 0.5 gpl. Barium Sulphate $\left(\mathrm{BaSO}_{4}\right)$ are formed due to existence of lower concentrations of sulphate ions and thus, solubility of these scale is low.

Petroleum industry approximately spends $\$ 1,000,000$ every year on problems of scale deposition depending on the plant size and it is a major cause for decline in production worldwide (Mackay, 2003). Methods for treating these problems have been limited and lately inefficient. Scale formation must be followed by a competent and productive removal technique. Presently available techniques of scale removal include mechanical and chemical approaches, depending on scale location and physical properties of respective scales.

The rest of the paper is organized as follows: Problem Statement are presented in Section II. Scale Development 
(Sources and Cases) are presented in Section III. Concluding remarks are given in section IV.

\section{PROBLEM STATEMENT}

There are discrete environmental concerns associated with using chemical methods. Like chemical techniques, most mechanical approaches have a narrow applicable range and choosing the appropriate method relies on the well and scale deposit. However, the use of high-pressure water sprays bypasses the drawbacks of both mechanical and chemical methods, and this thesis proposes to approach the problem in this way.
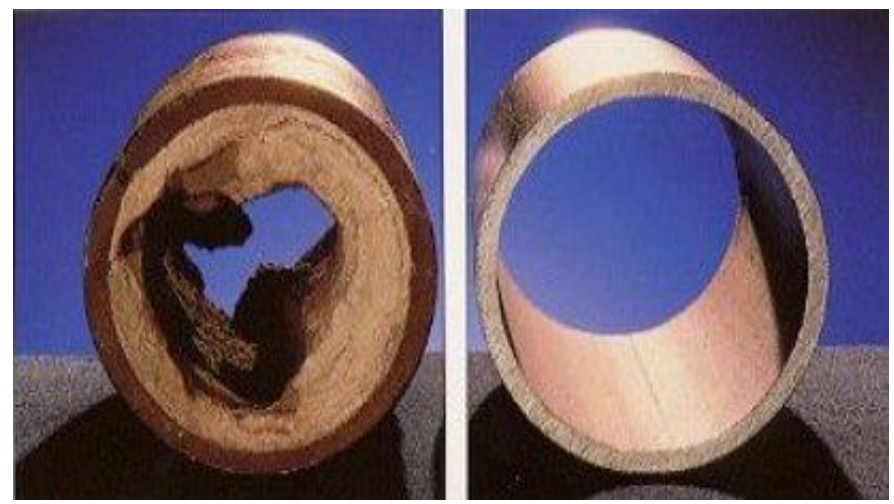

Figure 1: Diagram representing Scale deposit (EMEC- The Egyptian Mud Engineering \& Amp, 2016)

\section{SCALE DEVELOPMENT (SOURCES AND CASES)}

\section{A. Scale Identification}

Analyzing the composition of scale deposits is one of the fundamental actions that must be taken to develop an efficient programme for scale removal.

\section{B. Surface Equipment and Production Tubing}

Scale developed across production tubing is approximately few centimeters thick and comprises of crystals larger than one centimeter. This scale deposition results in increment of the surface roughness of the tubing, thereby lowering the production by downsizing the area of flow (Fletcher et al., 1999). Lower area of the well becomes inaccessible due to rapid increase in mineral growth and ultimately blocking the flow from the tubing. Production falls drastically due to the increase in driving pressure. Chemical composition of scale deposited in the tubing varies widely and encompasses different layers. These are commonly wax or Asphaltene layer and may be also composed of carbonates and iron sulphides.

\section{Wellbore Matrix}

The scale deposition near the wellbore zone are generally sulphides and carbonates with minute particle size (microns) rather than centimeters as observed in production tubing. These are generally deposited after subsequent span of shutting the well and is typically seen as skin. Rate of production can be easily increased by treatment using chemical dissolvers (acids).

\section{Scale Detection}

There are plentiful evidences of scale which can be detected from production tubing samples by core analysis using X-ray. Hard scales such as Barium Sulphate $\left(\mathrm{BaSO}_{4}\right)$ are usually detected by gamma-ray log interpretation due to precipitation of radioactive radium with scale (Fletcher et al., 1999). Other detecting techniques such as NODAL analysis is also employed to demonstrate scale in tubing applicable in cases when tubing constraints are realized. Drastic shift in concentrations of ions such as $\mathrm{Ba}^{\wedge}(2+)$ or $\mathrm{SO} \__{-} 4^{\wedge}(2-)$ followed by reduction in oil production indicates breaking through of injection water and outbreak of scale formation. It is quite advantageous to detect warning of scale formation at an early stage as wells can be completely accumulated with scale within a time span of 24 hours or even less. Recently, BP Amoco developed an effective scale management scheme that employs electrochemical sensors for detection of potential scale build-up. These sensors are susceptible to alteration in $\mathrm{pH}$, pressure, temperature and chloride ion concentrations.

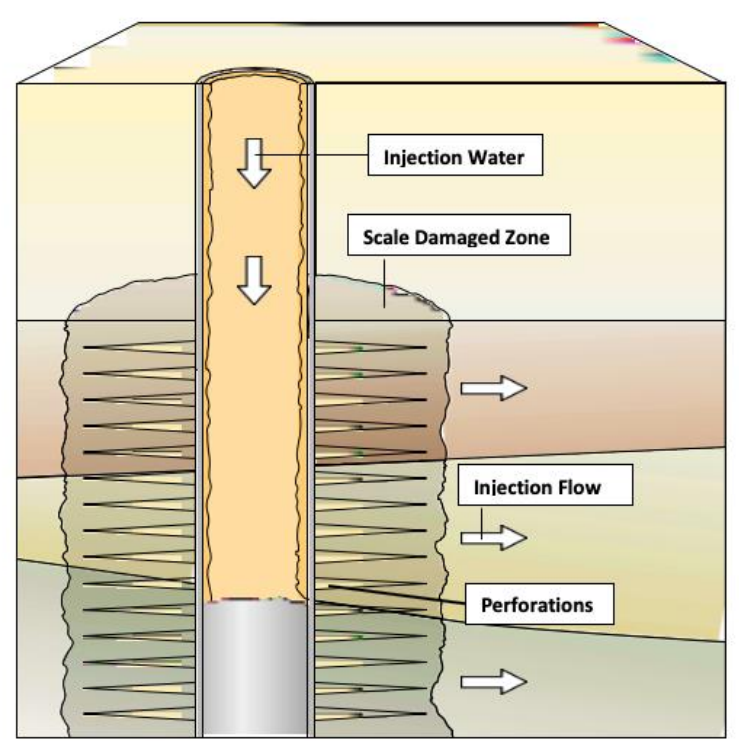

Figure 2: Injection Well Damage (Malcolm A. Kelland, 2014) 
Published Online April 2020 in IJEAST (http://www.ijeast.com)

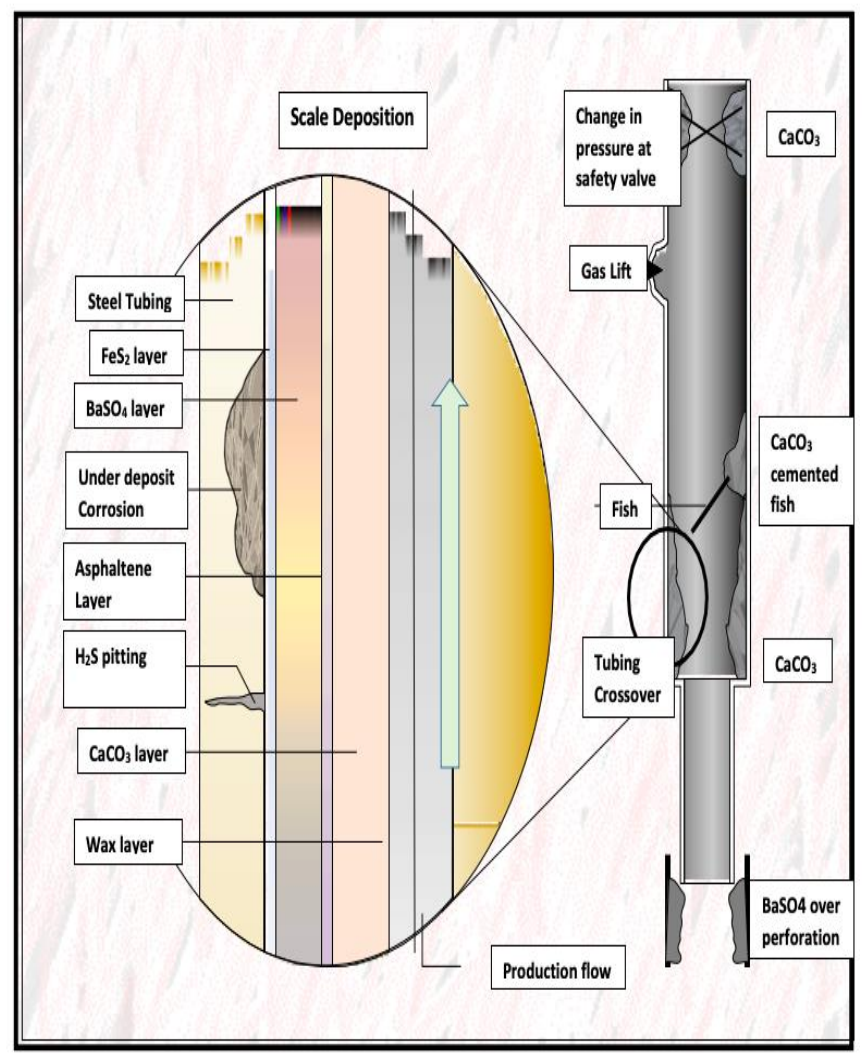

Figure 3: Scale Deposition in Tubing (Fletcher et al., 1999)

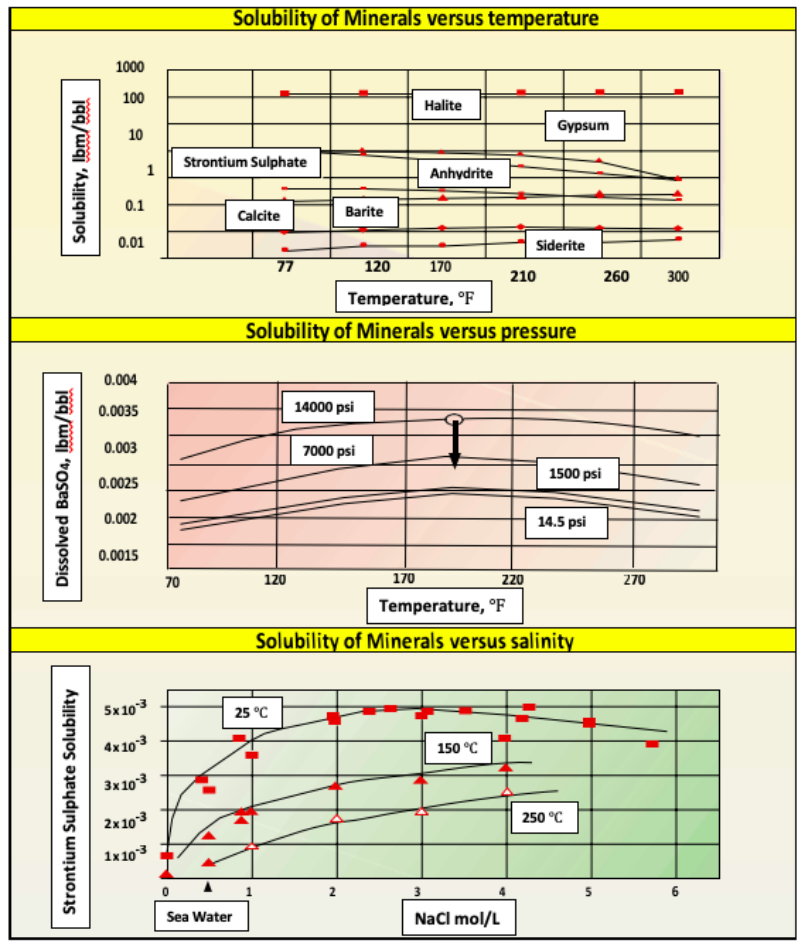

Figure 4: Mineral solubilities versus temperature/pressure/salinity (Johannes Karl Fink, 2003)

\section{METHODOLOGY}

This section provides a synopsis of the research work done in order to achieve the objectives of this study.

A. Components for the set up

- Water Tank

- Pump

- Unloading Valves

- Safety Valves

- Pressure Gauge

- Roller Bearings

- Spray Nozzles.

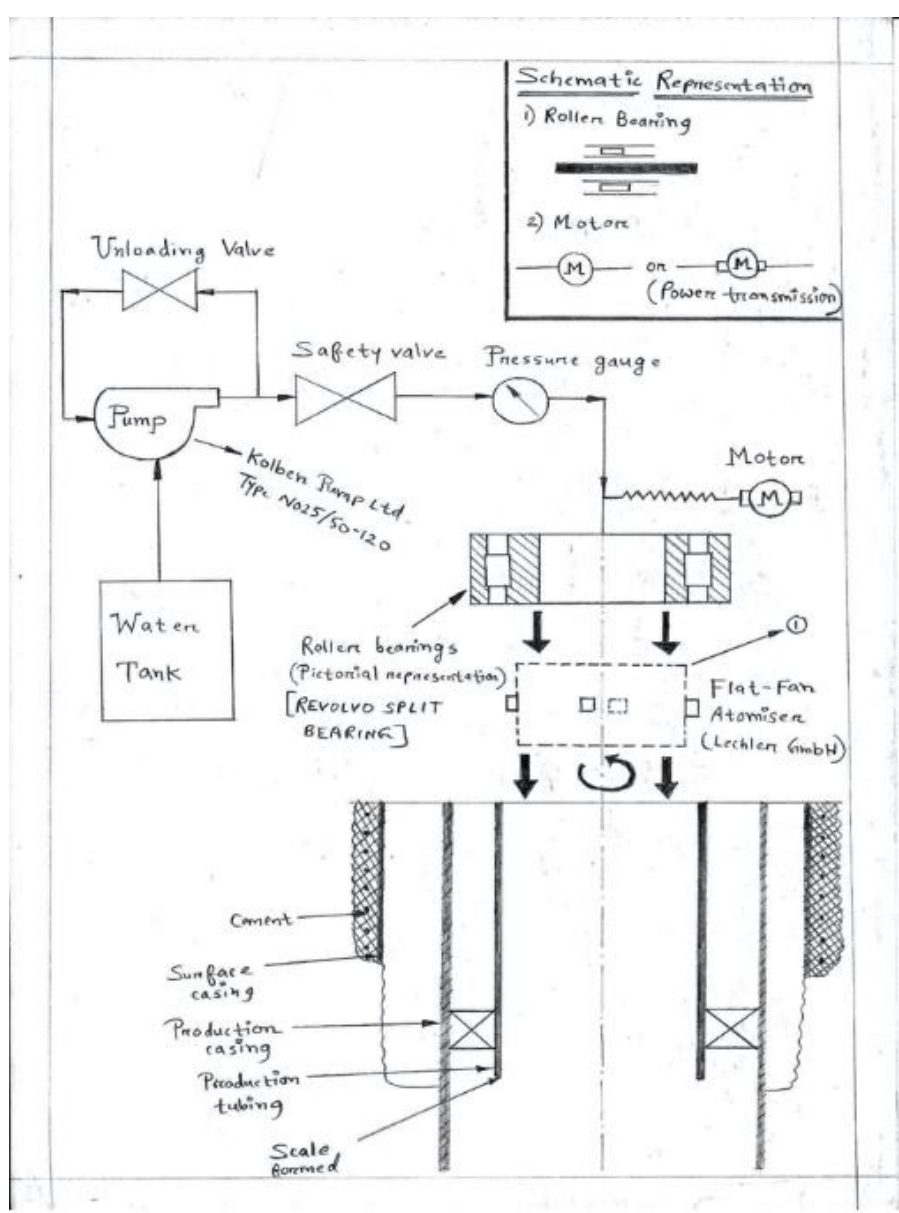

Figure 5: Schematic arrangement of nozzle system 


\section{EXPERIMENT AND RESULT}

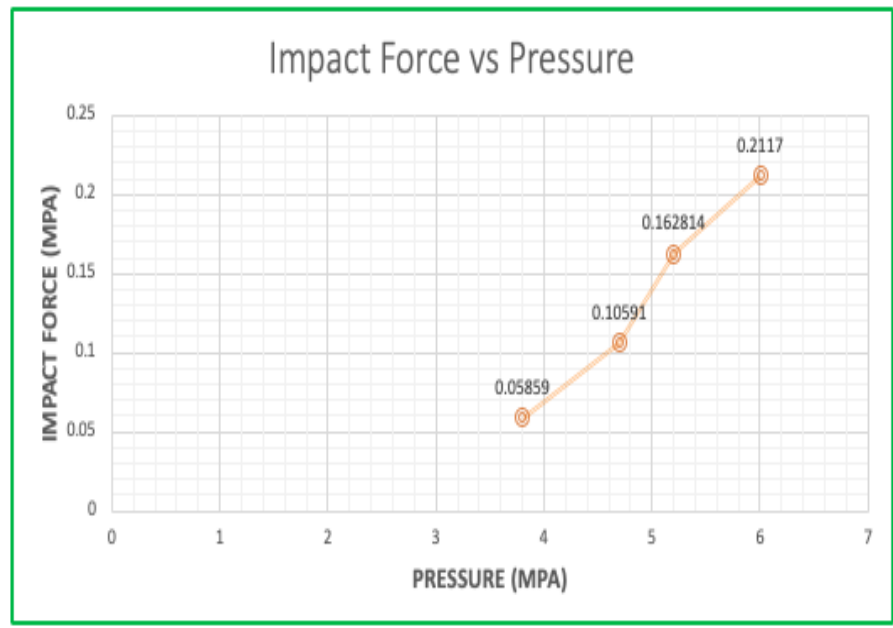

Figure 6: Variation of impact force as a function of pressure

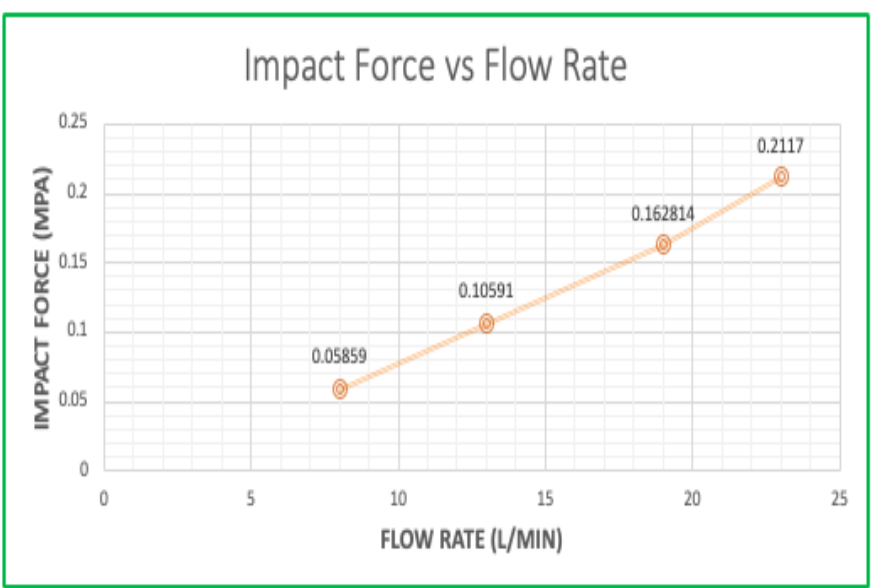

Figure 7: Variation of impact force as a function of flow rate

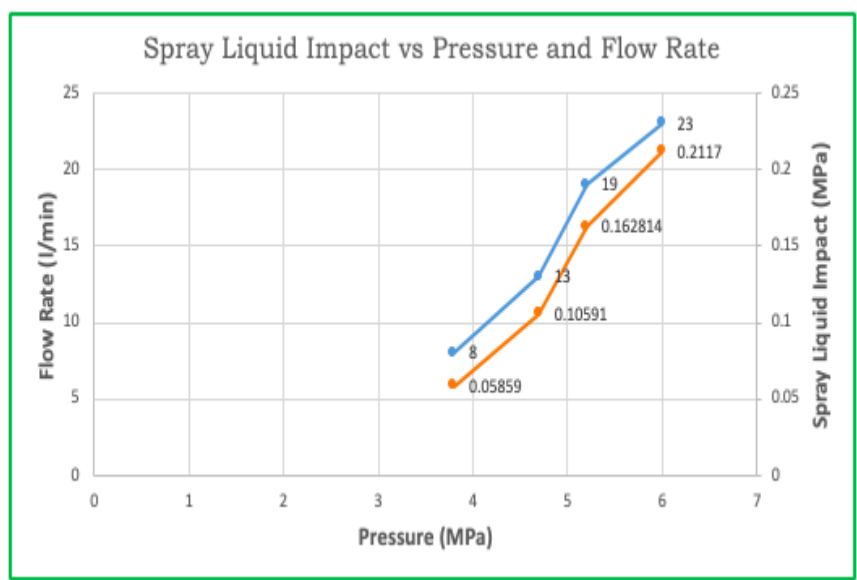

Figure 8: Variation of impact force as a function of pressure and flow rate
We have designed a schematic arrangement of a nozzle system for scale removal comprising of vital components such as water tank, pump, unloading valve, safety valve, pressure gauge. Motor, roller bearing and flat fan atomizers. We have specified the design configurations for every component supported with appropriate operating conditions. We have outlined a schematic structured engineering layout of a typical flat fan atomizer which is employed for this set up and modelled it using SolidWorks software application. We have also designed a Flanged 4-Bolt Round roller bearing and furnished the working mechanism for every individual component as well as the entire assembled arrangement. We have studied and investigated about basic characteristics of spray, spray patterns and spray performance considerations which is most suitable for the designed compiled model.

The effect of water pressure and flow rate on the spray impact is significantly important. To study the impact pressure generated by spray, a number of mathematical calculations have been carried out. In these calculations, water pressure and flow rate with initial values of $3.8 \mathrm{MPa}$ and $81 / \mathrm{min}$ was used for computation. These were followed by desired pressures and flow rates of 4.7 MPa and 13 1/min, 5.2 MPa and 19 1/min and $6 \mathrm{MPa}$ and $23 \mathrm{l} / \mathrm{min}$ respectively. From the results, it can be deduced that scale removal in production tubing (may be soft scale or hard scale) banks primarily on factors such as type of atomizers (flat fan atomizer), water supply pressure, flow rate, number of atomizers and spray liquid impact force. However, if requisite experimental procedure is implemented for this designed set up, factors such as spray time can also play a significant role in this regard.

\section{CONCLUSION}

Scales are basically soluble salts sparingly precipitated at the well surface. It usually materializes due to establishment of supersaturated regime. Scale formation causes problems across down hole wells, pipelines as well as processing units installed at the platform. Scales, if remains untreated, can result in worst case scenarios such as complete blockage of wells, pipelines including the processing machinery. As it is eminently undesirable, scale prevention is imperative. Developing a basic understanding of the background of scale is quite paramount for removing scale in an eco-friendly way. Wrong choices of scale removal technique can result in more scaling. HSE (Health, Security and Environment) is vital across all industrial firms. Some of the scale removal method (Chemical methods) represents health hazard and must be avoided to a greater extent.

The work carried out in this study focused on employing high pressure water spraying (flat fan atomizers) which has the following advantages:

- Eco-friendly

- Adequate spray liquid impact for scale removal 
- Minimal proportion of liquid needed

- Productive technique at minimized cost

- Explicit control on spray liquid impact to prevent damage of production tubing

The following overall conclusions can be jotted down from this study undertaken:

- A new designed nozzle system was introduced in this study that combined varied mechanical components which enhances the scale removal operations to a considerable extent.

- A unique design of high-pressure flat fan water spray was designed and implemented for scale removal in production tubing.

- Critical investigation and analysis were carried out for designing a circular ring which comprises of the atomizers (dimensions and material type).

- A detailed model of roller bearing was outlined and was attached to the motor for automatic control of the spray atomizers and generate uniform spray distribution.

- Experimental data (G.G Nasr et al., 2012) were retrieved and corresponding calculations were carried out to determine spray liquid impact.

- It was also found that results obtained closely matches with the previous studies undertaken in this aspect. (G.G Nasr et al., 2012)

\section{REFERENCES}

1. Guskova, I.A. (2011). Design and Development of technological solutions to the problem formation of organic deposits in the changed conditions of technogenic deposits of oil. PhD Thesis, TATNIPI, Bugulma

2. Allaga, A. D., Wu, G., Sharama, M. M. and Lake, W. L. (1992). Barium and Calcium Sulphate Precipitation and Migration inside Sandpacks. SPE Formation

3. Evaluation. SPE19675:79-86

4. Chen, T., Neville, A. and Yuan, M. (2004). Effect of PPCA and DETPMP Inhibitor Blends on $\mathrm{CaCO} 3$ Scale Formation. The 6th International Symposium on Oilfield Scale. May

5. 26-27. Aberdeen, UK: SPE 87442, 1-7.

6. Mackay, J.E. (2005). Scale inhibitor application in Injection Wells to protect against Damage to Production Wells: when does it work?. The SPE European Formation Damage Conference. May 25-27. Scheveningen, Netherlands: SPE 95022, 1-9.
7. Mackay, J.E., Collins, R.I. and Jordan, M. M. (2003). PWRI: Scale Formation Risk Assessment and Management. The SPE 5th International Symposium on Oilfield

8. Scale. January 29-30. Aberdeen, UK: SPE 80385, 118.

9. Mitchel, W.R., Grist, M.D. and Boyle, J. M. (1980). Chemical Treatments Associated With North Sea Projects. Journal of Petroleum Technology: SPE 7880, 904-912. 